\title{
Nitric Oxide Synthase Imunolabeling in the Molluscan CNS and Peripheral Tissues
}

\author{
W. J. Hurst,* L. L. Moroz, $\dagger^{\prime} \ddagger^{1}$ M. U. Gillette,* and R. Gilletteł \\ *Department of Cell and Structural Biology, University of Illinois, Urbana, Illinois 61801; tWhitney Laboratory, \\ University of Florida, 9505 Ocean Shore Boulevard, St. Augustine, Florida 32086-8623; and łDepartment \\ of Molecular and Integrative Physiology, University of Illinois, U rbana, Illinois 61801
}

NOS immunoreactivity was assayed in CNS and peripheral tissues of the sea slugs Pleurobranchaea californica, Tritonia diomedea and Aplysia californica using different antisera against mammalian nitric oxide synthase in Western blots. Polyclonal anti-nNOS labeled at 250, 185, 170, 155, 100, 75, and $65 \mathrm{kD}$ in extracts of Pleurobranchaea CNS, salivary gland and esophagus but not of gills or muscle. The labeling pattern for Tritonia in bands at 250, 200, 120/110, 100, 69, 65, and 60 kD differed somewhat. Anti-nNOS labeling in Aplysia was markedly different, with bands labeled only at 69 and 60 kD in CNS extracts, and at 200, 190, 69 and 60 kD in salivary and esophagus extracts. The wide variation in NOS immunoreactivity is consistent with species differences in tissue localization and biochemical properties of molluscan NOS isoforms. $\odot 1999$ Academic Press

Key Words: neuronal NOS; inducible NOS; endothelial NOS; Pleurobranchaea; Aplysia; Tritonia; gastropoda.

Nitric oxide (NO) modulates multiple aspects of synaptic transmission and neuron excitability in invertebrate nervous systems $(1,2,3)$. Presently, the tissue distributions and range of properties of nitric oxide synthase (NOS) and its isoforms are in early stages of investigation in invertebrates, and results from diverse laboratories suggest substantial variability may exist. For arthropods, a $\mathrm{Ca}^{2+}$-dependent constitutive NOS resembling the neuronal NOS of mammals has been demonstrated in the CNS of crayfishes (4) and insects $(5,6)$. Coelenterates also have a neuronal type NOS whose activity is substantially $\mathrm{Ca}^{2+}$-dependent (7). In molluscs, NOS activity has been measured in CNS of the opisthobranchs Aplysia and Pleurobranchaea (8), and of the pulmonates Lymnaea $(9,10)$ and Helix $(11)$.

\footnotetext{
${ }^{1}$ Present address and to whom correspondence should be addressed. Fax: (904) 461-4008. E-mail: moroz@whitney.ufl.edu.

Abbreviations used: NO, nitric oxide; NOS, nitric oxide synthase; CNS, central nervous system.
}

Measured in terms of arginine to citrulline conversion (substrate and coproduct, respectively) in homogenate extracts, NOS activity in the opisthobranchs was substantial but not $\mathrm{Ca}^{2+}$ dependent (8). In contrast, NOS activity measured in affinity purified extracts of Lymnaea CNS was decreased by at least half in $\mathrm{Ca}^{2+}$-free sal ine (10), while NOS activity from Helix ganglia similarly assayed was reduced by $90 \%$ by $\mathrm{Ca}^{2+}$ removal (11). While these results might reflect in part the different methods of extract preparations, they also suggest that the character of NOS in the CNS may vary across species.

As a part of a comparative analysis of NOS in molIuscS, we have characterized NOS immunoreactivity in CNS and peripheral tissues of three marine opisthobranchs commonly used in CNS research; the notaspid Pleurobranchaea californica, the nudibranch Tritonia di omedea, and the cephalospidean Aplysia californica. In Western blot assays of tissue extracts using antisera against the three mammalian NOS isoforms: neuronal NOS (nNOS, type I), endothelial NOS (eNOS, type III) (12), and the inducible NOS (iNOS; type II), we found wide variations among both species and tissues in antigen staining, antigen molecular weight and relative levels of NOS antigenicity, as described below.

\section{MATERIALS AND METHODS}

Specimens of P. californica MacFarland, 1966 (Opisthobranchia: N otaspidea, $n=11$ ); and T. diomedea Bergh, 1894 (Opisthobranchia: Nudibranchia, $\mathrm{n}=4$ ) and A. californica Cooper, 1863 (Opisthobranchia: Anaspidea, $n=5$ ) were collected from the Pacific coast of California and maintained in artificial sea water for up to a month before experiments. CNS and peripheral tissues were dissected, blotted on filter paper, weighed and quickly frozen on dry ice. All samples were kept at $-70^{\circ} \mathrm{C}$ for up to 36 hours until use.

Protein extracts were prepared from frozen tissue by addition of enough $0.1 \%$ SDS to make samples approximately $20 \mathrm{mg}$ protein $/ \mathrm{ml}$. Samples were kept on ice, homogenized by grinding and sonicated $(3 \times 30 \mathrm{sec})$. I nsoluble material was removed by brief centrifugation $(14,000 \mathrm{rpm}, 1 \mathrm{~min})$. Protein concentration of each sample was determined by Bradford assay prior to adding an equal volumes of $2 \times$ denaturing buffer $(0.125 \mathrm{M}$ Tris- $\mathrm{HCl}, \mathrm{pH} 6.8,1 \%$ SDS, 30\% glyc- 
Pleuobranchaea californica cerebropleural ganglion extract probed by Western blot with:

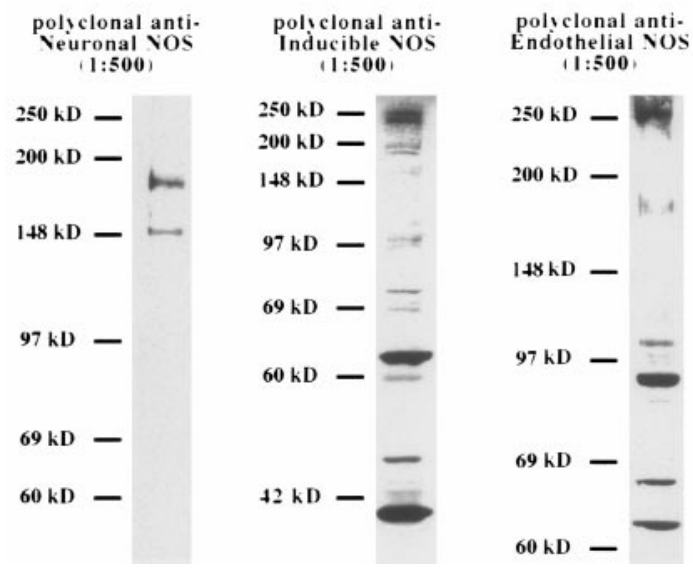

FIG. 1. NOS immunoreactivity in the CNS of Pleurobranchaea californica probed with polyclonal antisera against three mammalian NOS isoforms.

erol, 5\% 2-mercaptethanol, $0.1 \%$ bromphenol blue). Samples were boiled ( $3 \mathrm{~min}$ ) and subjected to standard SDS-PAGE electrophoresis. $10 \mu \mathrm{g}$ protein were loaded into each lane. Gels were transferred to nitrocellulose by standard methods. Parallel gels were run and subjected to silver staining (Bio-Rad) to assess relative protein loading. Nitrocellulose blots were probed with peptide-derived antibodies from Transduction Labs, including polyclonal rabbit anti-nNOS (1:500); polyclonal rabbit anti-eNOS (1:500); polyclonal rabbit antiiNOS (1:500); monoclonal mouse anti-nNOS (1:2500); monoclonal mouse anti-eNOS (1:2500); and, monoclonal mouse anti-iNOS (1:2500). Additionally, a rabbit polyclonal antibody against the entire nNOS protein (1:1000) was tested (13). I mmunoreactivity was visualized using horseradish peroxidase-linked goat anti-rabbit (Chemicon) or goat anti-mouse (Zymed) secondary antibody and ECL fluorescence detection system (Amersham). Specificity of immunoreactive bands was determined by pre-absorbing nNOS antibodies with $25 \mathrm{~g} / \mathrm{ml}$ nNOS purified from baculovirus-infected insect cells (14) for $60 \mathrm{~min}$ at room temperature before probing nitrocellulose blot.

Rat cerebellum, pituitary tissue, human endothelial cells and mouse macrophage extracts were used as appropriate positive controls (15) and run simultaneously with molluscan tissues in each experiment. The pedal muscles, buccal muscles and esophagus from Pleurobranchaea were used as negative controls, since our earlier measures of specifically fixative resistant NADPH-diaphorase reactivity (a marker for NOS) and detectable NOS activity in L-arginine/ L-citrulline conversion were negative $(8,16)$.

\section{RESULTS}

NOS immunolabeling in Pleurobranchaea. We compared monoclonal (3 peptide-derived) and polyclonal ( 3 peptide-derived; 1 against the entire protein) antisera specific to each of the NOS isoforms against extracts from CNS by Western analysis. In all experiments, polyclonal antisera against mammalian NOS isoforms were more effective than monoclonal antisera at labeling specific protein bands of molluscan tissue extracts. Monoclonal antisera did label many of the same bands on blots as the respective polyclonal anti- sera, however, to a much lower intensity. The most intense specific labeling was observed using neuronal anti-NOS polyclonal antisera (Fig. 1). Both anti-nNOS antisera produced similar results; however, the peptide-derived polyclonal antisera identified fewer bands at a higher intensity than other antisera used. CNS samples exhibited strong immunoreactivity mainly in $\geq 250$ and $155 \mathrm{kD}$ bands. Among the peripheral tissues, the $155 \mathrm{kD}$ band was found only in the gill. Muscle showed immunoreactivity at relatively low molecular weights ( $\leq 110 / 100 \mathrm{kD})$, whereas both high $(\geq 250,185$, 170) and low molecular weight nNOS immunoreactive proteins $(\leq 100 \mathrm{kD})$ were observed in salivary gland and the esophagus.

In all tissues tested, the 155, 110, and $100 \mathrm{kD}$ bands disappeared when nNOS antisera was pre-absorbed with bacterially-expressed nNOS (data not shown). Blots also indicated crossreactivity with lower molecular weight proteins ( $\leq 75$ kD) which displayed no appreciable loss of immunoreactivity during preabsorption experiments. Binding of nNOS antisera to lower molecular weight proteins has been demonstrated previously (15). These bands may represent related proteins or breakdown products of full length NOS proteins. Possibly, pre-absorption may have been insufficient to fully deplete primary nNOS antisera of antibodies which cross-react with these species.

Both eNOS and iNOS antisera labeled several proteins in the CNS with different molecular masses compared to nNOS immunolabeling (Table 1, Fig. 1). Antisera to iNOS recognized a large number of bands ranging from 40 to $250 \mathrm{kD}$. Most of these bands were considered non-specific as they were not lost when antibody was pre-absorbed with a mammalian NOS. Similar patterns were also observed with eNOS antisera, but the labeling was slightly less intense.

TABLE 1

A Comparison of the Principal Immunoreactive Bands in the CNS of Three Molluscan Species Using Anti-NOS Peptide-Derived Polyclonal Antisera

\begin{tabular}{|c|c|c|c|c|}
\hline \multicolumn{5}{|c|}{$\begin{array}{l}\text { Approximate molecular weight of cross-reactive bands (kD) } \\
\text { Pleurobranchaea }\end{array}$} \\
\hline nNOS & eNOS & iNOS & $\begin{array}{l}\text { Aplysia } \\
\text { californica } \\
\text { (nNOS) }\end{array}$ & $\begin{array}{c}\text { Tritonia } \\
\text { diomedea } \\
\text { (nNOS) }\end{array}$ \\
\hline \multirow[t]{2}{*}{$\geq 250$} & $\geq 250$ & $\geq 250$ & - & 250 \\
\hline & & 190 & - & 200 \\
\hline \multirow{7}{*}{155} & 185 & 185 & - & - \\
\hline & & & - & - \\
\hline & 110 & 100 & - & $130,120,110,100$ \\
\hline & 90 & & 85 & 85 \\
\hline & 67,63 & 65 & $69,63,60$ & $70-60$ \\
\hline & & 50 & - & - \\
\hline & & 40 & - & - \\
\hline
\end{tabular}


A.
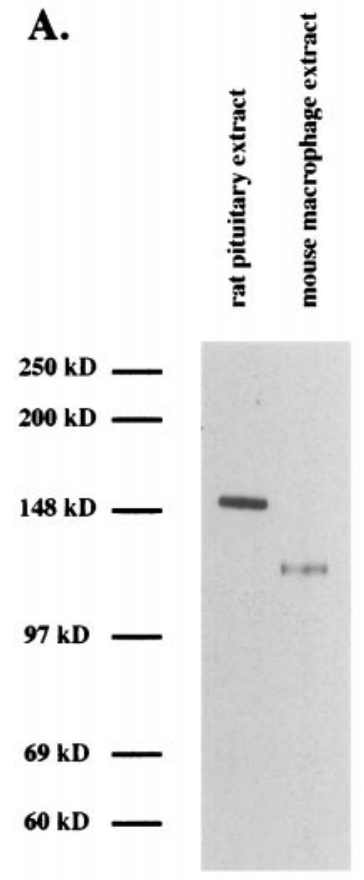
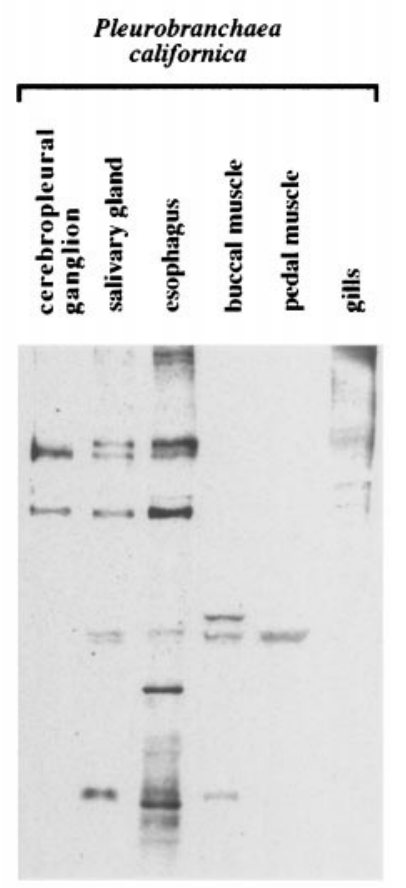

B.
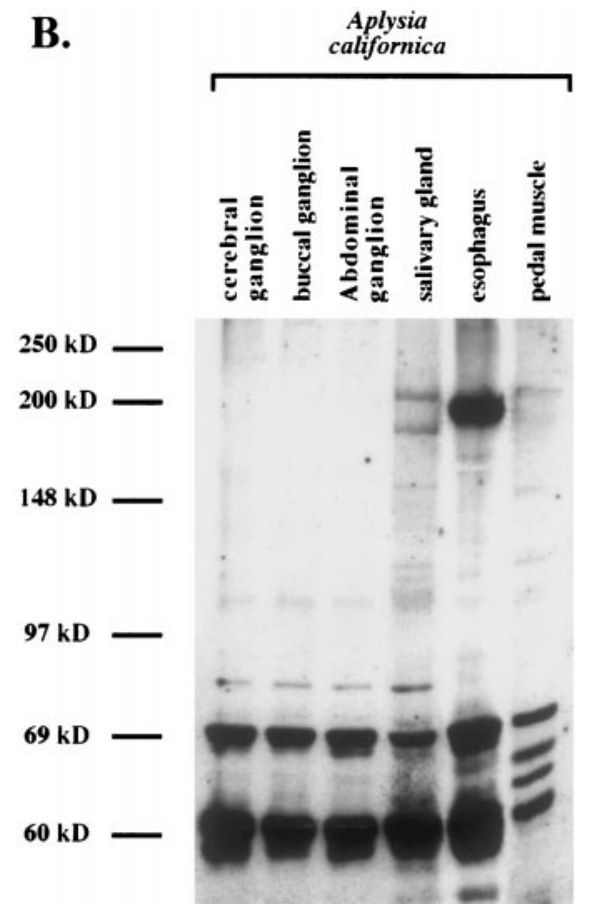
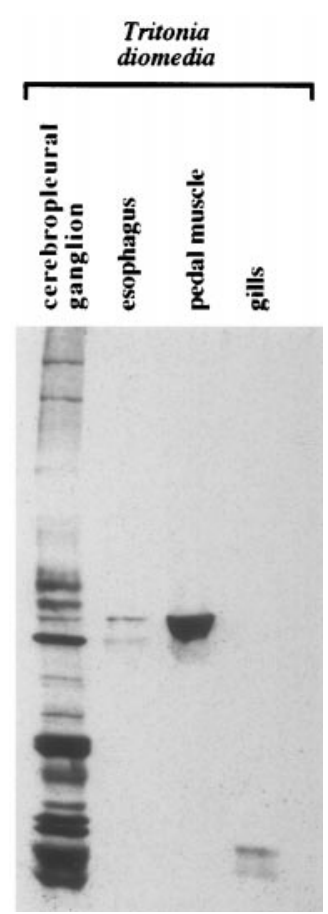

FIG. 2. A comparison of NOS immunoreactive bands in peripheral tissues from different molluscan species using peptide-derived polyclonal antisera. Rat pituitary and mouse macrophage extracts were used as controls for mammalian nNOS and iNOS, respectively. (A) Extracts from Pleurobranchaea. (B) Extracts from Aplysia and Tritonia.

NOS immunolabeling in Aplysia and Tritonia. Patterns of nNOS-immunolabeling in the CNS of Aplysia differed markedly from Pleurobranchaea (Table 1, Fig. 2); Tritonia also differed in labeling pattern, but less so than Aplysia. None of the NOS-immunoreactive bands in Aplysia corresponded to labeled Pleurobranchaea proteins. Blots of Aplysia CNS samples displayed only 69 and 60 kD bands, whereas 200, 190 and 69, 60 kD bands were found in salivary and esophagus extracts. In Tritonia CNS extracts, anti-nNOS antiserum labeled proteins at 250,200,120/110,100,69, 65 and 60 kD. In peripheral tissues only $110 / 100$ and 60 kD proteins were observed.

\section{DISCUSSION}

Selectivity of the anti-NOS antisera has been previously tested in a range of mammalian tissues. In mammals nNOS is a $155 \mathrm{kD}$ protein whose labeling is selectively out-competed in pre-absorption experiments. Labeling of low molecular weight proteins (around 65 kD) in rat cerebellum and pituitary tissues as well as in molluscan preparations was not affected by preabsorption experiments, suggesting that their labeling was not specifically related to NOS immunoreactivity. Labeling of a 155 kD (133 kD) protein in Pleurobranchaea CNS was quite specific, since labeling was selectively removed in preadsorbtion experiments. This protein was detected only in the CNS, corresponding to the specific tissue localization of NOS activity in biochemical measures (15). Thus, this protein is a likely candidate for a molluscan form of neuronal NOS. In the insect Drosophila the estimated molecular weight for NOS is in the same range, $130-150 \operatorname{kD}(17,18)$, whereas a higher MW has been reported for nNOS from Lymnaea (10).

Comparison of the observed immunolabeling in Pleurobranchaea with the previously described distribution of NADPH diaphorase activity, a histochemical marker for NOS, showed appreciable similarity with one notable difference. That is, significant NADPH diaphorase activity was observed in central neurons, salivary gland and gills but was only weak or non-detectable in peripheral structures (16); however, intense NOS immunolabeling was found in Pleurobranchaea esophagus at 250,185 , and $\sim 150 \mathrm{kD}$. Potentially, the immunoreactivity of the esophagus represents inactive enzyme in this tissue. In salivary gland, intense NADPH-d labeling coincided with intense NOS immunolabeling of bands at $>250,190$ and $185 \mathrm{kD}$, but not at $155 \mathrm{kD}$ (Table 2).

It is of substantial interest that such different patterns of nNOS immunoreactivity were observed in the opisthobranchs Aplysia, Tritonia and Pleurobranchaea, which also markedly differed in their tissue patterns of NADPH-d reactivity. I mmunolabeled high molecular weight proteins were noted from multiple tissues of both Aplysia and Tritonia, but the 155 kD 


\section{TABLE 2}

A Comparison of the Principal Immunoreactive Bands in Peripheral Tissues from Three Molluscan Species Using Peptide-Derived Polyclonal NOS Antisera

Approximate molecular weight of cross-reactive bands (kD)

\begin{tabular}{|c|c|c|c|}
\hline $\begin{array}{l}\text { Species: } \\
\text { Tissue }\end{array}$ & $\begin{array}{l}\text { Pleurobranchaea } \\
\text { californica } \\
\text { (nNOS) }\end{array}$ & $\begin{array}{l}\text { Aplysia } \\
\text { californica } \\
\text { (nNOS) }\end{array}$ & $\begin{array}{r}\text { Tritonia } \\
\text { diomedea } \\
\text { (nNOS) }\end{array}$ \\
\hline Buccal muscles & $\begin{array}{c}110,100 \\
65\end{array}$ & NT & NT \\
\hline \multirow[t]{2}{*}{ Pedal muscles } & - & 200 & - \\
\hline & 100 & - & 110 \\
\hline \multirow{6}{*}{ Esophagus } & $\geq \overline{250}$ & $\begin{array}{c}69,67,65,63 \\
-\end{array}$ & - \\
\hline & 190 & 190 & - \\
\hline & 185 & - & - \\
\hline & 100 & - & 110,100 \\
\hline & 75 & - & - \\
\hline & 65 & - & - \\
\hline \multirow[t]{4}{*}{ Gills } & $\geq 250$ & NT & - \\
\hline & $190-185$ & & - \\
\hline & 155 & & - \\
\hline & $\overline{250}$ & & 60 \\
\hline \multirow{4}{*}{ Salivary glands } & $\begin{array}{r}\geq 250 \\
190\end{array}$ & 200 & NT \\
\hline & 185 & 180 & \\
\hline & 100 & - & \\
\hline & 65 & $69,63,60$ & \\
\hline
\end{tabular}

protein found in Pleurobranchaea was not detected. In molluscs, NOS activity is broadly manifested in tissues and central neurons involved in food handling and feeding behavior, including salivary glands, esophagus, chemosensory epithelia, and specific CNS elements (19, 20, 21, 22). Aplysia, Tritonia and Pleurobranchaea vary broadly in their feeding ecology, being respectively a grazing herbivore, a grazing sessile cnidarian specialist, and an opportunistic general predator. These correlations suggest to us that the marked differences in tissue localization and molecular weights of NOS immunoreactivity may be related to differences in the role of NOS in food-handling. We suggest that such differences may have been involved in broad evolutionary changes in the adaptive radiation and properties of NOS isoforms among the gastropod molluscS.

These results suggest the presence of NOS isoforms that may vary broadly both among tissues and across molluscan species. We hope that ongoing efforts to characterize NOS activity in diverse tissues and species in our's and others' laboratories will provide useful information that can further physiological studies of the regulatory actions of NO and its synthetic enzyme in molluscan model systems.

\section{AKNOWLEDGMENTS}

This research was supported by NIH research grants NS33230 to M.U.G., MH59339 to R.G., and, in part, by INTAS (\#93-3504), and International Research Scholars Program (\#75195-540101; HHMI) and NIH 39103-01 grants to L.L.M. We thank Brend Mayer (University of Graz) for anti-nNOS and baculovirus-expressed nNOS.

\section{REFERENCES}

1. Colasanti, M., and Venturini, G. (1998) Mol. Neurobiol. 17, 157174.

2. J acklet, J . (1997) Invert. Neurosci. 3, 1-14.

3. Moroz, L. L., Gillette, R., and Sweedler, J . V. (1999) J . Exp. Biol. 202, 333-341.

4. J ohansson, K. U. I., and Carlberg, M. (1994) Brain Res. 649, 36- 42.

5. Bicker, G. (1998) Trends Neurosci. 21, 349-355.

6. Muller, U. (1997) Prog. Neurobiol. 51, 363-381.

7. Colasanti, M., Venturini, G., Merante, A., Musci, G., and Lauro, G. M. (1997) J . Neurosci. 17, 493- 499.

8. Moroz, L. L., Chen, D., Gillette, M. U., and Gillette, R. (1996) J. Neurochem. 66, 873- 876.

9. Elofsson, R., Carlberg, M., Moroz, L. L., Nezlin, L., and Sakharov, D. A. (1993) Neuroreport 4, 279-282.

10. S. A. Korneev, Piper, M. R., Picot, J ., Phillips, R., Korneeva, E. I., and O'Shea, M. (1998) J . Neurobiol. 35, 65-76.

11. Huang, S., Kerschbaum, H. H., Engel, E., and Hermann, A. (1997) J . Neurochem. 69, 2516-2528.

12. Dinerman, J . L., Dawson, T. M., Schell, M. J ., Snowman, A., and Snyder, S. H. (1994) Proc. Natl. Acad. Sci. USA 91, 4214- 4218.

13. Kummer, W., Fischer, A., Mundel, P., Mayer, B., Hoba, B., Philillin, B., and Preissler, U. (1992) Neuroreport 3, 653- 655.

14. Harterneck, C., Klatt, P., Schmidt, K., and Mayer, B. (1994) Biochem. J . 299, 247-252.

15. Chen, D., Hurst, W. J ., Ding, J . M., Faiman, L. E., Mayer, B., and Gillette, M. U. (1996) J . Neurochem. 68, 855- 861.

16. Moroz, L. L., and Gillette, R. (1996) J . Comp. Neurol. 367, 607- 622.

17. Nighorn, A., Gibson, N. J ., Rivers, D. M., Hildebrand, J . G., and Morton, D. B. (1998) J . Neurosci. 18, 7244-7255.

18. Regulski, M., and Tully, T. (1995) Proc. Natl. Acad. Sci. USA 92, 9072-9076.

19. Moroz, L. L., Park, J. H., and Winlow, W. (1993) Neuroreport 4, 643- 646.

20. Moroz, L. L., and Gillette, R. (1996) in Neurobiology of Invertebrates: Simple and Complex Regulatory Systems (Salanki, J., S-Rozsa, K., and Elekes, K., Eds.), pp. 169-182, Akademia Kiado, Budapest.

21. Elphick, M. R., Kemenes, G., Staras, K., and O'Shea, M. (1995) J. Neurosci. 15, 7653-7664.

22. Gelperin, A. (1994) Nature 369, 61- 63. 